\title{
Our Experience in Epidural Analgesia Following Large Abdominal Surgeries.
}

\author{
Nehat Baftiu1, R.Baftiu1 \\ https://doi.org/10.32391/ajtes.v3i2.65
}

\begin{abstract}
Background: Epidural analgesia is a gold standard in post-operative pain control in patients undergoing large abdominal interventions. Different studies report a failure ratio of epidural analgesia of $20-32 \%$.

The aim of this study is to analyze the success rate of epidural analgesia and its consequences in patients that have been subject to large abdominal surgeries.

Materials and methods: We have prospectively collected the data of 50 patients that were subject to open abdominal surgeries during a 2 year timeframe (September 2015 September 2017) at University Clinical Center of Kosovo. Experienced anesthesiologists inserted the epidural catheters. A dedicated team used the Verbal Scale to collect the data regarding post-operative pain during coughing or moving. The success rate of eidural catheter was measured in terms of: the scale of pain, pulmonary post-operative infection and length of hospital stay.

Results: The study group included 33 males and 17 females, most of whom were subject to liver surgery. The secondary liver formations $(70 \%)$, primary tumours $(20 \%)$ as well as beningn liver disorders $(10 \%)$ were an indication for liver resection. Large resections ( $\geq 3$ segments) were completed in $44 \%$ of patients, small liver resections were $(\leq 2$ segments) completed in $48 \%$ of patients, while $8 \%$ of patients were considered inoperative. Epidural analgesia was successful in 46 patients (92\%). Bacterial colonisation of the catheter was observed in only one case. There were no neurological complications. $5(10 \%)$ patients showed radiologicalsigns of a pulmonary infection. Three patients $(6 \%)$ had surgical wound infection. One patient died of hepatic insufficiency after massive right liver resection and cholecystectomy due to gallbladder carcinoma. The average length of hospital stay was 6 days.

Conclusions: Our experience concludes that epidural analgesia is a safe and effective way of pain relief after abdominal surgeries.

Keywords: epidural analgesia, open abdominal surgery, acute pain, prevention.
\end{abstract}

*Corresponding Author: Nehat Baftiu

=凶Email: nehatbaftiu@hotmail.com

1 University Clinical Center of Kosovo, Prishtina, Republic of Kosovo. 


\section{Full Text}

\section{Introduction}

Epidural analgesia provides a regional pain control through neuroaxial blocade. It is estimated that epidural analgesia offers a better pain control (especially pain due to movements) at the beggining of the post-operative period, following large abdominal surgeries in contrast to patient controlled analgesia.

The duration of post-operative intubation, post-operative mechanical ventilation, myocardial infarction, gastric and renal complications are more rare when epidural analgesia is applied. There are several physiological factors that reason the decrease of such complication after using this technique. Epidural analgesia allows adequate early post-operative mobilisation, thus reducing early cardiopulmonary complications.

This is why epidural analgesia is as a gold standard in pain control following large abdominal surgeries. It has gained an important role, especially after the implementation of the rehabilitation programs.

However, some studies have shown that a considerable part of the epidural catheters $(20-32 \%)$ fail party or in total immediately after the post-operative period, thus resulting in a non adequate pain control.

Liver resection due to benign or malign disorders is a very frequent surgical procedure. Pain folloqing surgery may compromise pulmonary function, epsecially after large incisions near the diafragm. Hepatectomy is very often performed under low venous pressure in order te reduce blood loss from the hepatic veins. Hypotension from neuraxial blockade might be neccessary to provide a low venous pressure.

Bilateral subcostal incision, starting from the median axillary line on the right up to outter border of rectus muscle on the left and xiphoid process superiorly is the classical incision for large abdominal surgeries such as hepatectomy. The central part of the incision represents the weakest point of the abdominal wall, that predisposes for post-operative wound dehiscence and incisional hernia.

Epidural analgesia is considered to the less effective, the higher the incision on the abdominal wall. That is why modified incisions are made, including J incision (excluding the left subcostal component) and bilateral subcostal incision(exluding the superior central part) that are advantageous in reducing pain and hence in less post-operative respiratory consequences.

Some of the neurological adverse effects of epidural analgesia such as epidural hematoma and epidural abscess might have very great neurological conseqeunces, are fortunately very rare. Post-operative coagulopathies may be noticed more frequently after hepatectomy surgeries.

\section{Aim \\ The aim of our study was to analyze the success rate of epidural analgesia and its consequences in patients that have been subject to large abdominal surgeries ( including those performed using bilateral modified subcostal incision).}


We aimed as well to find any possible relation among epidural analgesia failure, length of hospital stay, and complications such as: pulmonary infections and wound infections.

\section{Materials and methods}

We have prospectively collected the data of 50 patients that were subject to open abdominal surgeries during a 2 year timeframe (September 2015 September 2017) at University Clinical Center of Kosovo. Epidural catheter was successfully inserted in all of our patients. Our variables included: patient's characteristics, surgical indication, sixe of incision of lives resection, epidural catheter data, results of post-operative pain, complications and length of hospital stay. All of the patients were subject to bilateral subcostal incision without involving the cental line( the superior xiphoid process part). Liver resection was classified as large ( $\geq 3$ segments) and ( $\leq 2$ segments). All the patients that underwent large abdominal surgery remained for 24 hours after surgery at instensive care unit. The patients were as well categorized accordinh to their disease: beningn, primary malignant and secondary malignanat (metastases).

\section{Epidural catheter insertion and management}

Experienced anesthesiologists inserted the epidural catheters, at T7-T8 intervertbral space levels while the patients were awake. Bupivacaine
$(0,1 \%)$ and Fentanyl $(2 \mu \mathrm{g} / \mathrm{mL})$ were used as infusions. All the patients had the possibility to self administer this infusion injecting $3 \mathrm{ml}$ of bolus (up to two boluses in one hour).

First, a continuous infusion of $3-12 \mathrm{ml} / \mathrm{h}$ was applied. The quantity of the infusion was based on the clinical data regarding the scale of pain. Pain scales were collected and documented by a specializes nurse at specific time intervals. If the patient referred for a strong pain, then the nurse applied a bolus of $5 \mathrm{ml}$ for the infusion.

All the patients received Paracetamol (1gr every $6 \mathrm{~h}$ ) as a standard auxilliary analgesic. The pain scale was monitored from our team when the patients were moving or coughing by using the Verbal Scale (0-no pain, 1- low pain, 2- average pain, 3-strong pain). Removal of epidural analgesia and opioid administration to control pain were considered as a failure of epidural analgesia. Epidural analgesia was removed one day after the continuous infusion was stopped, usually the third or the forth post-operative day. The clooting factors were controlled on the day of catheter removal. If the tip of the catheter showed signs of infections it was immediately removed and it was sent for microbiological testing.

The data regarding hepatic insuficiency, pilmonary infections and wound infections were recorded. A pulmonary infections was considered when the clinical signs and radiological signs were present. A wound infection was considered when the clinical signs and positive microbiological results were present. The success rate of eidural catheter was measured in terms of: the 
scale of pain, pulmonary post-operative infection and length of hospital stay. All the data were collected in Excel and were analyzed using the SPSS programme.

\section{Results}

The study group included 33 males and 17 females. The mean age was 66 years old (32-84 years old, with an average of 67 and a standard deviation (SD) of 9.2 years ). Indications for the intervention were metastases $(69 \%, \mathrm{n}=35)$, primary tumors $(20 \%, \mathrm{n}=10)$ and benignity $(11 \%$, $\mathrm{n}=5$ ). From the metastasis, the majority were colorectal $90 \%(\mathrm{n}=44)$ and the others derived from carcinoid $(\mathrm{n}=2)$, breast cancer $(n=10)$, anal squamous cells carcinoma $(\mathrm{n}=1)$ and bladder cancer $(n=1)$. The primary liver tumors included hepatocellular carcinoma $(\mathrm{HCC}, \mathrm{n}=7)$, cholangiocarcinoma $(\mathrm{n}=3)$ and cholecysto carcinoma $(n=4)$. Major and minor interventions were done in respectively $44 \%(\mathrm{n}=22)$ and $48 \%$ $(n=24)$ of patients, wheras $8 \%(n=4)$ were inoperable. The patient' $\mathrm{s}$ characteristics and the complications are illustrated in the table below (Table 1)

\begin{tabular}{|c|c|c|c|c|}
\hline Variables & & $\begin{array}{l}\text { Major } \\
\text { interventions }\end{array}$ & $\begin{array}{l}\text { Minor } \\
\text { interventions }\end{array}$ & Inoperable \\
\hline Number (\%) & & $22(44 \%)$ & $24(48 \%)$ & $4(8 \%)$ \\
\hline \multirow[t]{2}{*}{ Age (years) } & Average & 67 & 69 & 59 \\
\hline & $\begin{array}{l}\text { Minimum- } \\
\text { Maximum }\end{array}$ & $57-81$ & $32-84$ & 49-77 \\
\hline \multirow[t]{2}{*}{ Gender } & Males & 13 & 16 & 1 \\
\hline & Females & 9 & 8 & 3 \\
\hline \multirow[t]{2}{*}{ Indications } & Benign & 2 & 3 & 0 \\
\hline & Malign & 20 & 21 & 4 \\
\hline \multirow[t]{2}{*}{ Epidural } & Success & 21 & 21 & 4 \\
\hline & Failure & 1 & 3 & 0 \\
\hline $\begin{array}{l}\text { Pulmonary } \\
\text { infection }\end{array}$ & & 3 & 1 & 0 \\
\hline Wound infection & & 2 & 1 & 0 \\
\hline \multirow[t]{2}{*}{$\begin{array}{l}\text { Length of hospital } \\
\text { stay }\end{array}$} & On average & 7 & 6 & 5.5 \\
\hline & $\begin{array}{l}\text { Minimum- } \\
\text { Махітum }\end{array}$ & $5-27$ & $4-20$ & 3-9 \\
\hline
\end{tabular}

Table 1: Patient's characteristics and the complications

Epidural analgesia resulted successful in 46 patients $(92 \%)$. The failure of epidural analgesia was noticed only in male patients $(n=4)$. The analgesia was not successful in 2 patients due to unilateral block. There was also initially an unilateral block in 3 patients, but the grade of pain was reduced in a low one ( grade 1) after redeployment of the epidural catheter ( aseptic traction of 1 $\mathrm{cm}$ ) and bolus administration of the medications by the nurses. These cases 
were not included in the group of failures. All the patients that failed with epidural analgesia were given a continuously morphine therapy. The grade of postoperative pain were collected for each patient, every day after the epidural catheterization. It resulted that 16 patients didn't have any kind of pain (lowest pain grade 0 ). The

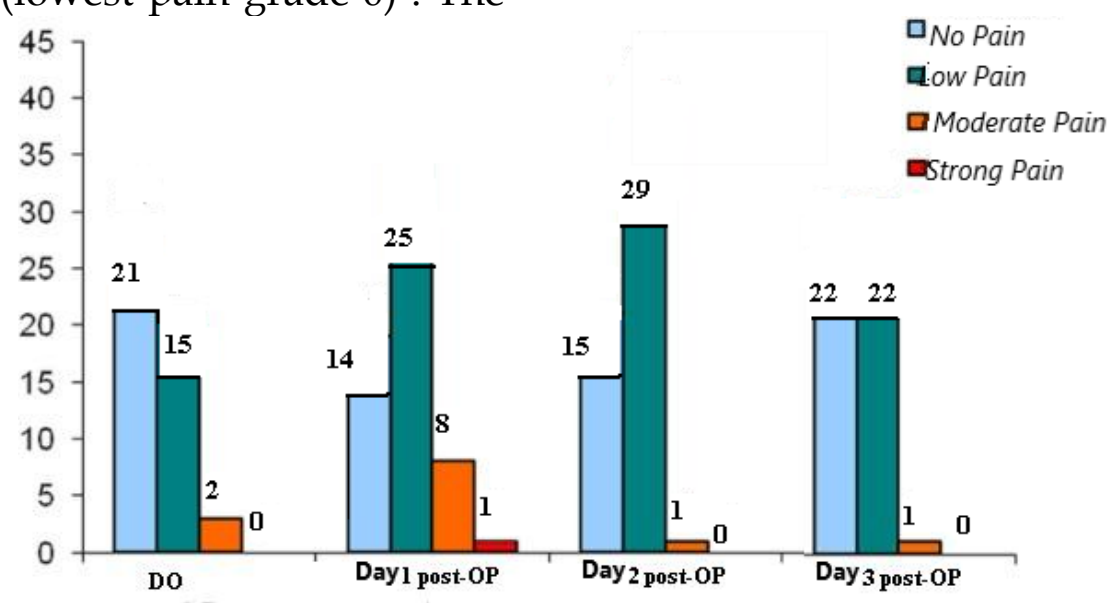

most common pain grade was 1 ( mild pain ) found in 23 patients, than pain grade 2 ( moderated pain) in 5 patients and severe pain (grade 3 ) in 5 patients. The frequency of the pain's grade of successfully catheterized patients, until the 3 day post intervention is illustrated in Figure 1.

Figure 1: Grade of pain on post-operative days

None of the patients developed epidural hematoma or abscess . Bacterial colonization of the catheter was also not found in any of the patients . There weren't any neurological complications . The average time of keeping the epidural catheter after the intervention was 3 days ( $\min 2$ days, max 5 , average 3.4 with a SD 0.98)

4 Patients $(7 \%)$ developed a pulmonary infection which was confirmed by radiology . 4 Patients developed wound infection. A patient died as a result of hepatic failure due to resection of a massive part of the right hepatic lobe and cholecyst because of cholecyst carcinoma . (1.4\%).

Patients had a mean hospitalization period of 6 days ( varying from 3 to 27 days, $\mathrm{SD}=4.6$ ). There wasn't any significant difference in the hospitalization time based on the age , sex, main surgery indication or epidural analgesia .The hepatic resection size had an important impact in the hospitalization time, the ones who resected a larger portion stayed more in hospital. Also pulmonary infections played an important role .

\section{Discussions}

The majority of operations in our country are realized by a big abdominal incision . In this study all the interventions were done from specialist through a standard bilateral subcostal incision. Even though the epidural thoracic catheter is considered to produce a bilateral sensorial block in the 
upper abdominal part, it is seen that the upper the incision is done the less controlled pain is and the greater is the risk of pulmonary complications . The midline incision causes a major abdominal traction and a greater damage of the abdominal wall, that delays the pulmonary recovery . Anyway it should be noticed that this study analyzed the effectiveness of analgesia in standard incisions .

In our study epidural analgesia was productive in treating post operation pain in $92 \%$ of patients. In different studies it has been reported of failure of this analgesia in $20 \%$ of patients who had liver cancer. Our study showed that when the catheter was placed by a trained team with the lead of an anesthetist epidural analgesia was more productive .

Epidural analgesia is considered to be the gold standard post operative analgesia of upper abdominal operations, because it is thought that epidural analgesia is the best option of immediate analgesia .

Hypotension can be very often caused by epidural analgesia, which can be considered a priority when we want to reduce venous pressure to also reduce bleeding during hepatic surgery.

The administration of large amounts of IV fluids is well known in these kind of interventions, but could be easily prevented by a well prepared staff . Even though the grade of pulmonary infections in our study was low $(7 \%)$, this complication was a very important factor that prolonged the days of hospitalization . Due to the reduction of opioids when we use epidural analgesia there is a better function of gastrointestinal tract, pulmonary tract and an easier recovery after operation.

Neurological complications such as hematoma, abscess which can be life threatening and to worry about were very rare. Even though there was a patient with epidural contamination, there was no evidence of infection and no neurological complications

The well trained staff and the use of modern catheters was of a great help. The mean hospitalization period in this study was 6 days, prolonged by the size of liver resection .

The weakness of our study is still the standardization of the surgical incision, the operation technic, and the prospective collection of the data. Some limitations in our study could be the reduced number of patients and the fact that the stud was only conducted in one hospital center.

\section{Conlcusions}

Our experience concludes that epidural analgesia is a safe and effective way of pain relief after abdominal surgeries. We have reache a $92 \%$ success rate in patients that were subject to large abdominal surgeries (standard subcostal incision excluding the central superior xiphoi process line). Neurological adverse effects might have great consequences, but since they are very rare, we have not encountered such complications in our study, neither have found these ones in similar studies.

The epidural catheter is very effective when it is inserted routinely from experienced anesthesiologists and it is managed by teams that are traind in pain control. 


\section{References}

1. Nishimori M, Ballantyne JC, Low $\mathrm{JH}$. Epidural pain relief versus systemic opioid-based pain relief for abdominal aortic surgery. Cochrane Database Syst Rev 2006; 3: CD005059.[PubMed]

2. Kehlet H. Modification of responses to surgery by neural blockade: clinical implications. In: Cousins $\mathrm{M}$, Bridenbaugh $\mathrm{P}$, editors. (eds) Neural blockade in clinical anesthesia and management of pain, 2nd edn. Philadelphia, PA: J. B. Lippincott \& Co, 1988, pp. 145-188.

3. McLeod G, Davies H, Munnoch $\mathrm{N}$, et al. Postoperative pain relief using thoracic epidural analgesia: outstanding success and disappointing failures. Anaesthesia 2001; 56(1): 75-81.[PubMed]

4. Hughes KS, Rosenstein RB, Songhorabodi $\mathrm{S}$, et al. Resection of the liver for colorectal carcinoma metastases. A multiinstitutional study of long-term survivors. Dis Colon Rectum1988; 31(1): 1-4. [PMC free article] [PubMed]

5. Kanas GP, Taylor A, Primrose JN, et al. Survival after liver resection in metastatic colorectal cancer: review and meta-analysis of prognostic factors. Clin Epidemiol 2012; 4: 283-301. [PMC free article] [PubMed]

6. Scheele J, Stangl R, AltendorfHofmann A, et al. Indicators of prognosis after hepatic resection for colorectal secondaries. Surgery 1991; 110(1): 13-29. [PubMed]

7. Choti MA, Sitzmann JV, Tiburi $\mathrm{MF}$, et al. Trends in long-term survival following liver resection for hepatic colorectal metastases. Ann

Surg 2002; 235(6): 759-766.[PMC free article] [PubMed]

8. Jamison RL, Donohue JH, Nagorney DM, et al. Hepatic resection for metastatic colorectal cancer results in cure for some patients. Arch Surg 1997; 132(5): 505-510, discussion 511. [PubMed]

9. Pawlik TM, Scoggins CR, Zorzi $\mathrm{D}$, et al. Effect of surgical margin status on survival and site of recurrence after hepatic resection for colorectal metastases. Ann Surg 2005; 241(5): $\quad$ 715-722, discussion 722-724. [PMC free article] [PubMed]

10. Mayo SC, Pulitano C, Marques H, et al. Surgical management of patients with synchronous colorectal liver metastasis: a multicenter international analysis. J Am Coll Surg2013; 216(4): $\quad$ 707-716, discussion 716-718. [PMC free article] [PubMed]

11. Bromage PR, Camporesi E, Chestnut D. Epidural narcotics for postoperative analgesia.Anesth

Analg 1980; 59(7):

473480. [PubMed]

12. Van der Auwera D, Verborgh C, Camu F. Analgesic and cardiorespiratory effects of 
epidural sufentanil and morphine in humans. Anesth Analg 1987; 66(10):

9991003. [PubMed]

13. Melendez JA, Arslan V, Fischer $\mathrm{ME}$, et al. Perioperative outcomes of major hepatic resections under low central venous pressure anesthesia: blood loss, blood transfusion, and the risk of postoperative renal dysfunction. J Am Coll Surg 1998; 187(6): 620625. [PubMed]

14. D'Angelica M, Maddineni S, Fong Y, et al. Optimal abdominal incision for partial hepatectomy: increased late complications with Mercedes-type incisions compared to extended right subcostal incisions. World J Surg 2006; 30(3): $\quad 410$ 418. [PubMed]

15. Armstrong PJ, Burgess RW. Choice of incision and pain following gallbladder surgery. $\mathrm{Br}$ J $\quad$ Surg 1990; 77(7): $\quad$ 746748. [PubMed]

16. Halasz NA. Vertical vs horizontal laparotomies I. Early postoperative comparisons. Arch Surg 1964; 88: 911-914. [PubMed]

17. Proske JM, Zieren J, Muller JM. Transverse versus midline incision for upper abdominal surgery. Surg Today 2005; 35(2): 117-121. [PubMed]
18. Cook TM, Counsell D, Wildsmith JA. Major complications of central neuraxial block: report on the Third National Audit Project of the Royal College of Anaesthetists. Br Anaesth2009; 102(2): 179 190. [PubMed]

19. Tsui SL, Yong $\mathrm{BH}, \mathrm{Ng} \mathrm{KF}$, et al. Delayed epidural catheter removal: the impact of postoperative coagulopathy. Anaesth Intensive Care 2004; 32(5): $\quad$ 630636. [PubMed]

20. Dureuil B, Cantineau JP, Desmonts JM. Effects of upper or lower abdominal surgery on diaphragmatic function. $\mathrm{Br} \mathrm{J}$ Anaesth 1987; 59(10): $\quad$ 12301235. [PubMed]

21. De Pietri L, Siniscalchi A, Reggiani A, et al. The use of intrathecal morphine for postoperative pain relief after liver resection: a comparison with epidural analgesia. Anesth Analg 2006; 102(4): $\quad$ 11571163. [PubMed]

22. Warner DO, Warner MA, Ritman EL. Human chest wall function during epidural anesthesia. Anesthesiology 1996; 85(4): 761-773. [PubMed] 